\title{
Using Mobile Application Intercessions to Decrease Prenatal Mortality in Developing Countries: A Systematic Review
}

\author{
https://doi.org/10.3991/ijim.v12i7.9635 \\ Chen Kim Lim $\left.{ }^{(}\right)$, Kian Lam Tan, Martin Shafiihuna Haufiku \\ Universiti Pendidikan Sultan Idris (UPSI), Tanjong Malim, Perak, Malaysia \\ kimefskik.upsi .edu.my
}

\begin{abstract}
Mobile phones are increasingly used in health systems in developing countries, and innovative technology solutions have great potential to overcome barriers of access to maternal health care. The objective of this study is to conduct a systematic review of the literature to ascertain what evidence exists for the effectiveness of mobile applications to decrease prenatal mortality through behavioural modification in developing countries. The study is essential in examining and illuminating certain aspects of the usage of mobile applications to improve prenatal care in developing areas and would, therefore, open up immense possibilities for prenatal care applications to improve essential precautional maternal services and in turn possibly lower the mortality rate in developing countries. Database searches and an intensive screening process were conducted before reviewing the full text of 34 articles and finally, nine articles that met all the inclusion criteria were selected. The study found that most of the included studies utilised text message suggestions to impact persistent conduct change in patients and all led in African nations. The review concluded that every one of the written reports appeared at any rate to show some proof of viability at changing conduct to decrease prenatal mortality. The policy infrastructure for funding, coordinating and guiding the sustainable adoption of precautional maternal services remains under-developed and that the integration of mobile health for prenatal health services has demonstrated positive outcomes.
\end{abstract}

Keywords-Mobile Applications; Antenatal Care; Prenatal Care; Developing Countries

\section{Introduction}

In recent year, the education, business and media sectors have been utilizing the aid of technologies in our daily lives. With the advancement in technology, it is no surprise that we are seeing an increase of applying technology within the health sector, especially the use of mobile applications in prenatal care. The number of people starting to use and understand mobile health services is growing higher daily. The terms eHealth and mHealth are used for the practice of medicine and health services through mobile devices and the Internet $[1,2]$. Mobile devices and the Internet are adopted by 
people and integrated into their everyday lives. Variety can be seen in today's accessible mHealth applications as mobile applications incorporate the utilization of mobile phones and the Internet for different things like the accumulation of clinical information, giving medical data to health experts, analysts and patients, and for the constant observing of patient vital signs and direct arrangement of care.

It is safe to claim that developing countries worldwide are experiencing a technological revolution with an increase in the number of mobile phone subscribers in SubSaharan Africa (17 million in 2000 to 650 million in 2011) [3]. Therefore, the healthcare systems could be strengthen by applying mobile applications in healthcare center itself [4]. Many pregnant women and unborn babies in developing countries die due to postponements in getting medical treatment [5]. Studies have suggested that the use of mobile applications might reduce such delays. It has come to light that expecting mothers frequently use the Internet and mobile applications as a source of information and thus medically accurate and improved smartphone applications might provide a way to specifically target this mHealth and eHealth user group. Prenatal care applications are used to track everything from gestation period to baby kicks per day whilst delivering user centered information about nutrition, healthy lifestyle and changes in maternal physiology and biology. These applications are not substitutes for a more hands on approach but rather are meant to supplement physical prenatal care.

Prenatal or antenatal care provides regular check-ups for both mother and child during the pregnancy stage. It is also known as a type of preventive healthcare where doctors and midwives can consistently treat and examine the mother and the child throughout the course of the pregnancy. This would certainly prevent potential health problems while promoting healthy lifestyles that benefit both mother and child until the baby is safely delivered. Medical information with regards to the maternal physiological changes during the pregnancy, biological changes, and prenatal nutrition including antenatal vitamins are provided to the pregnant women during the check-ups so that they are aware of what is now and next. During the regular check-ups, the doctors would recommend and provide proper advice to how the pregnant women can manage and adapt to the changes that lead to healthier lifestyle. By making the routine prenatal cares available, the prenatal mortality rates could be reduced. The prenatal cares also play and important role in reducing miscarriages, birth defects, low birth weight, neonatal infections as well as other preventable health problems. There is over half a million women die each year during pregnancy and in order to reduce the maternal mortality down to $75 \%$ by the year of 2015 , the Millennium Development Goals (MDGs) came into action. With MDG, after 15 years, significant progress could be reported in lowering child mortality rates in both the rural and urban areas. However, targets have not been met with matters and difference pertaining between lower resource settings as well as developed regions, instead recent report estimated maternal mortality to be 14 times higher in developing regions. The World Health Organization (WHO) recommends that pregnant women should all now receive at least four antenatal visits to spot and treat problems in advance. Many women however reluctant to receive the recommended four visits especially in developing countries where the WHO has reported in 2015 that around 825 women who died every day from problems in pregnancy and childbirth ( $99.4 \%$ of the total). 
Even with all the efforts that are being made to improve maternal care in developing countries, it is a known fact, that mortality rates are much higher in developing countries compared to developed countries. This imbalance is because these women do not have the necessary precautional services available to them. In developing countries only about $52 \%$ of the pregnant women receive the World Health Organization (WHO) recommended minimum of four prenatal visits. Families tend to utilize medicinal services when somebody is sick however much of the time exclude these helpful precautional services that are fundamental to enhance wellbeing as a result of shifting reasons, from an absence of medicinal offices to fiscal issues. It appears that poverty is the biggest issue contributing towards inadequate access to health care during pregnancy [6]. Free et al. observed that in the course of the mHealth studies that have been conducted, many are of poor quality, a few have a low threat of bias, and very few have discovered any clinically massive benefits brought forth by the interventions [6, 7]. The Lancet report of technologies for global health in 2002 has indicated that in low-income countries, there are only nine randomized controlled trials for mHealth [3]. This is one of the few reviews that explore the relationship between mobile applications and maternal mortality in developing countries. The findings from this study are critical to future mobile application intercession evaluation and development.

\section{Literature Review}

This section looks at what other authors have written about mobile application use in prenatal care. It also examines the study characteristics and key outcomes for each included article.

\subsection{Characteristics of Studies}

There are total of nine articles that satisfied the researcher's inclusion criteria: four of these studies were Randomized Controlled Trials (RCTs) [9, 10, 11, and 12]. Of the remaining studies one was observational in that it had no control group [15], two used a non-randomized control group $[14,16]$ and two that used a mixed methods $[13,17] .100 \%$ of the articles studied prenatal precautionary services in developing countries. Five of the studies used mobile application intercessions that sent messages and reminders to the patients directly whilst sending user defined educational messages [9, 10, 11, 12 and 13]. Five of the studies sent reminders to CHWs' phones to follow up with patients $[9,14,15,16$ and 17] and three of the studies are from Zanzibar $[9,10,11]$. Three of the studies included intercessions in the studies include sending information through SMS to the patients one way $[9,13,15]$ and in six studies making calls to health facilities $[9,10,11,14,16$ and 17]. 


\subsection{Finding by Intercession}

[9] reports a swell in skilled attendance at childbirth as $60 \%$ of the pregnant female in the intercession group received skilled attendance, and $47 \%$ in the control group (OR 5.73; 95\% CI 1.5121 .81 ). However, this was observed only in the urban women and not in the rural women. [10] observed that the use of cell phones by the pregnant women was associated with a swell in antenatal care attendance, and $44 \%$ of the women introduced to mobile application intercessions undergo four or more antenatal care visits in contrast to $31 \%$ of those who were not introduced (OR 2.39; $95 \% \mathrm{CI}$ $1.035 .55)$. [11] reported that greater number of women in the intervention group $(574 / 1311,43.8 \%)$ undergo the recommended four or more prenatal care visits than in the control group $(385 / 1239,31.1 \%)$. There were $72.8 \%$ of those who had not been introduced ( $\mathrm{pB} 0.001)$ to cellular health intercessions through telephone prompts and recommendations about their health was delivered in a health center [12]. Besides, in locations where the cellular phones had been allotted to women attending antenatal care utilized the primary healthcare facilities more than the area where cellular telephones had not been distributed (pB0.001) [14]. [15] reported that the rates of facility-based deliveries varied from a minimum rate before the intercession of $72 \%$. There is no statistically considerable distinction proven between the intercession and control groups for a SMS intervention in enhancing the antenatal health understanding although there was a considerable loss of $43 \%$ to follow-up as recorded throughout the study [13]. [16] also reported that the quality score elevated from 13.33 at baseline to 17.15 at end line $(p<0.0001)$. That was the most noteworthy advancement associated to health counseling. Health education had the best quality score swell from 5.45 to 8.67 points $(\mathrm{p}<0.001)$. All the research exhibited grounds that mobile application intercession had a tremendous impact on the patients' behaviour. Majority of the participants in the research contend that the intercessions enhance access to maternal information, whilst it decreased the expenses of getting access to care and facilitated referral. This review observed that some mobile application intercessions have adequate evidence to make topic-specific recommendations for scaling and broader implementation [9, 10, 11 and 12]. However the studies varied in quality and as such a portion of these outcomes cannot conclusively be accredited to the mobile application intercessions that were implemented for these studies alone.

\subsection{Finding for Decreasing Prenatal Mortality}

[15] reported that antepartum and postpartum hemorrhage where the most frequent danger sign, which accounted for $30 \%$ of emergency cases and three $(0.02 \%)$ maternal deaths and 137 infant deaths had been registered in the system. In line with[14], it was observed that regardless whether in the intervention region or the control region, there was no distinction in the incidence of the five predominant causes of maternal deaths. There are also 15 pairs of twins that accounted for $1 \%$ of pregnancies, 2 were stillborn, and 4 were early neonatal deaths [11]. Overall, 2482 children were live born, 54 were stillborn, and 36 died within the first 42 days of life and 69 children were prenatal deaths. The intercession was associated with a significant reduction in 
the outcome of prenatal mortality with an OR 0.50 (95\% CI $0.27-0.93)$. The other secondary outcomes showed an insignificant reduction in stillbirths (OR 0.65, 95\% CI $0.34-1.24$ ) and also an insignificant reduction in death of a child within 42 days (OR $0.79,95 \%$ CI 0.36-1.74). [12] reported a reduction in missed appointments in pregnant women using cell phones as only $3.6 \%$ of those exposed to mobile application intercessions had less than four antenatal visits, while $9.7 \%$ of those not exposed (p0.002). [17] reported that maternal death notification, has considerably improved with the intercession. The review found that the studies that included prenatal mortality findings all showed that mobile application intercessions decreased prenatal mortality $[11,12,14,15$ and 17].

\section{$3 \quad$ Methodology}

This section looks at the methodology used during this review. A systematic literature review was used because it identifies, critically evaluates and integrates issues caused by study differences, flaws or chance (sampling variation) in the findings of all-relevant, high-quality individual studies addressing this research question. It provides a comprehensive description of the sources used and the criteria with which articles were chosen for inclusion in this review. This literature review was conducted using keywords to search four databases, namely Emerald Insight, Taylor and Francis Online, PubMed and Cochrane Library. This method was used to identify the pertinent articles. Keywords: mobile applications, antenatal care, prenatal care and developing countries. For an article to achieve inclusion in the review, it had to fulfill the following inclusion criteria:

1. The study evaluated mobile application intercession aimed at increasing prenatal care attendance through behavior change;

2. The study was carried out in a developing country;

3. The study was published between January 1, 2012 and June 30, 2017 (5 years);

4. The study was available in English;

5. The study included behavior change, quality of care outcomes (i.e., studies were excluded that only assessed volition of the participants to obtain a mobile application intercession without enforcing it);

6. The study was a peer-reviewed article.

Only studies conducted in developing countries, as per World Economic Situation and Prospects (WESP) classification, were considered. This is on the grounds that WESP arranges all nations of the world into one of three general classes: developed economies, economies experiencing significant change and developing economies. Though examinations of the socioeconomic status within developing countries revealed inequities in access to resources and in light of this, the researcher screened manually to fulfill this criterion. The researcher also restricted non-English articles, this is only a limitation of this review and future reviews should include more languages, for a more comprehensive future review if feasible. The reason this standard was chosen was to ascertain that the included studies analyzed outcomes of existing 
mobile application intercessions and not frameworks and studies that have yet to be enforced. Finally deciding to include only peer reviewed articles aided in securing that, only higher quality studies were analyzed.
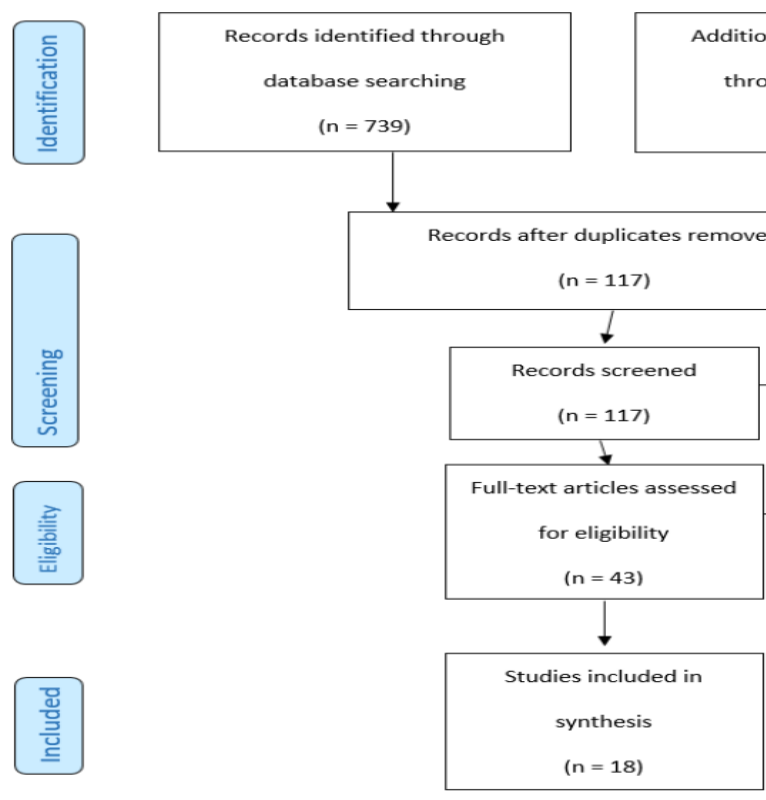

dditional records identified

through other sources

$(n=15)$

Fig. 1. Literature Search Iteration

Figure 1 summarised the results of the screening and selection as follows.

1. The search of the databases initially identified 739 articles.

2. The researcher removed all the duplicate articles, leaving 117.

3. The remaining articles were then screened by title and then by abstract, after which 34 articles remained.

4. The full text of the remaining 34 articles was reviewed to gauge if it met the inclusion criteria.

5. The researcher excluded 25 articles, reasons for this exclusion include, the study was not studying maternal mortality and prenatal care attendance $(\mathrm{n}=3)$; not studying mobile application intercession $(\mathrm{n}=5)$; the study was conducted in a developed country $(\mathrm{n}=2)$; not available in English the study did not include evaluation data and provided potential frameworks that were yet to be applied $(n=3)$; the study does not add any relevance to the review $(n=12)$.

\section{Discussions}

Variables that impact pregnant ladies towards incorporating prenatal care into their lives include promoting awareness about the importance of healthcare in general, 
prenatal care specifically and disease complications [20, 21]. Mobile phones allow for more detailed and reliable self-checking and following the newborn child advancement, for instance, users are prompted to record events as they occur by using multimedia mediums. Prompts in real time also allow automatic storing of geo-tagged and time-stamped entries in a personal database. Spatio-transient hints of practices consistently, week, or month can hugely expand a person's self-comprehension; likewise, these hints can expand clinician or supervisor knowledge of comprehensive behavioral make-up [22]. As health services in the developing nations are making venture at taking advantage of cell phones of their efforts to assist the ones in need, noticeably few very few of the research has been performed with the purpose of evaluating those efforts $[18,19]$. All of the studies used in this review confirmed the advantageous contributory consequences of mobile application intercession or cellular communication systems in reducing prenatal mortality in developing nations but the caliber of the evidence varied extensively. The outcomes were validated in diverse approaches by using the studies such as: (I) accelerated prenatal care attendance and (ii) reduced prenatal mortality.

There is strongest evidence exists for text and educational message delivered to the patients' mobile phones. The use of mobile phones was also found to reduce the delay experienced in receiving timely and appropriate care at the facilities. The four RCTs all found evidence of statistically meaningful increase in precautional maternal health care use, relative to their control group [9, 10, 11 and 12]. One RCT study found evidence of a significant reduction in the outcome of prenatal mortality [11]. A great deal of the evidence is primarily based on self-mentioned behavior changes from CHWs and sufferers, which isn't appropriately dependable to draw any sturdy conclusions at the effectiveness of mobile application intercessions [14, 15, 16 and 17]. One study reported that no significant difference for the control and intervention group in antenatal health knowledge levels at exit [13]. There was a clear variation in the quality of the studies, and different theoretical bases and designs had been utilized.

\section{Conclusion}

The literature available suggests that mobile application intercessions can contribute in reducing prenatal mortality in developing counties. The provision of high quality health services by mobile health applications shows the importance of mHealth. Mobile applications have a noteworthy part to play in ladies' wellbeing with their roles being extremely widespread, running from enhancing wellbeing practices to undertaking customized tests. Mobile phones applications make interest feasible for ladies to get to the care they require, including child birth and care, family planning and life skills [22]. However, the policy infrastructure for funding remains underdeveloped. The government should adopt precautional maternal services by coordinating and guiding the processes to ensure the sustainable adoption of the precautional maternal services. The combination of mobile health for prenatal health services has verified advantageous consequences, however the sustainability and scalability of operations calls for further comments and assessment of ongoing applications. Re- 
search needs to be centered on a blueprint for a cohesive system that follows women and children via maternal and baby health continuum [2].

\section{$6 \quad$ Limitations and Future Studies}

There exist blueprints in developing countries to curb the problem of prenatal mortality. Despite several solutions are being implemented, not many of them are being scaled up and execute the real test for mobile application intercessions [15]. The solutions should also extend its scalability and integration into the existing systems. More research recourses are needed to evaluate the effectiveness of mobile application intercessions for precautional maternal services. The researcher suggests more studies with an RCT design will help increase the quality of the evidence. Extending the period of some of the projects is essential to garner more extensive research. While we have been able to capture studies from various developing countries, all of them were conducted in Africa, which suggests that there is a need to broaden the context of future studies in other global regions. There is some existing evidence of the effectiveness of mobile application intercessions and it aids in identifying further research possibilities.

\section{$7 \quad$ References}

[1] Adibi, S. (Ed.). (2015). Mobile health: a technology road map (Vol. 5). Springer.

[2] Tamrat, T., \& Kachnowski, S. (2012). Special delivery: an analysis of mHealth in maternal and newborn health programs and their outcomes around the world. Maternal and child health journal, 16(5), 1092-1101. https://doi.org/10.1007/s10995-011-0836-3

[3] Yonazi, E., Kelly, T., Halewood, N., \& Blackman, C. (2012). The transformational use of information and communication technologies in Africa.

[4] Howitt, P., Darzi, A., Yang, G. Z., Ashrafian, H., Atun, R., Barlow, J., \& Cooke, G. S. (2012). Technologies for global health. The Lancet, 380(9840), 507-535. https://doi.org/10.1016/S0140-6736(12)61127-1

[5] The World Bank (2013). Country and lending groups. Retrieved August 10, 2017, from http://data.worldbank.org/about/country-and-lending-groups\#Low_income

[6] McPake, B., Witter, S., Ensor, T., Fustukian, S., Newlands, D., Martineau, T., \& Chirwa, Y. (2013). Removing financial barriers to access reproductive, maternal and newborn health services: the challenges and policy implications for human resources for health. Human Resources for Health, 11(1), 46. https://doi.org/10.1186/1478-4491-11-46

[7] Free, C., Phillips, G., Watson, L., Galli, L., Felix, L., Edwards, P., \& Haines, A. (2013). The effectiveness of mobile-health technologies to improve health care service deliv-ery processes: a systematic review and meta-analysis. PLoS medicine, 10(1), e1001363. https://doi.org/10.1371/journal.pmed.1001363

[8] Lund, S., Hemed, M., Nielsen, B. B., Said, A., Said, K., Makungu, M. H., \& Rasch, V. (2012). Mobile phones as a health communication tool to improve skilled attend-ance at delivery in Zanzibar: a cluster randomised controlled trial. BJOG: An Inter-national Journal of Obstetrics \& Gynaecology, 119(10), 1256-1264. https://doi.org/10.1111/j.1471$\underline{0528.2012 .03413 . x}$ 
[9] Lund, S., Nielsen, B. B., Hemed, M., Boas, I. M., Said, A., Said, K., \& Rasch, V. (2014a). Mobile phones improve antenatal care attendance in Zanzibar: a cluster randomized controlled trial. BMC pregnancy and childbirth, 14(1), 29. https://doi.org/10.1186/1471-239314-29

[10] Lund, S., Rasch, V., Hemed, M., Boas, I. M., Said, A., Said, K., \& Nielsen, B. B. (2014b). Mobile phone intervention reduces perinatal mortality in Zanzibar: second-ary outcomes of a cluster randomized controlled trial. JMIR mHealth and uHealth, 2(1). https://doi.org/10.2196/mhealth.2941

[11] Fedha, T. (2014). Impact of mobile telephone on maternal health service care: a case of Njoro division. Open Journal of Preventive Medicine, 4(05), 365. https://doi.org/10.4236/ ojpm.2014.45044

[12] Lau, Y. K., Cassidy, T., Hacking, D., Brittain, K., Haricharan, H. J., \& Heap, M. (2014). Antenatal health promotion via short message service at a Midwife Obstetrics Unit in South Africa: a mixed methods study. BMC pregnancy and childbirth, 14(1), 284. https://doi.org/10.1186/1471-2393-14-284

[13] Oyeyemi, S. O., \& Wynn, R. (2014). Giving cell phones to pregnant women and improving services may increase primary health facility utilization: a case-control study of a Nigerian project. Reproductive health, 11(1), 8. https://doi.org/10.1186/1742-4755-11-8

[14] Ngabo, F., Nguimfack, J., Nwaigwe, F., Mugeni, C., Muhoza, D., Wilson, D. R., \& Binagwaho, A. (2012). Designing and Implementing an Innovative SMS-based alert system (RapidSMS-MCH) to monitor pregnancy and reduce maternal and child deaths in Rwanda. The Pan African Medical Journal, 13.

[15] McNabb, M., Chukwu, E., Ojo, O., Shekhar, N., Gill, C. J., Salami, H., \& Jega, F. (2015). Assessment of the quality of antenatal care services provided by health workers using a mobile phone decision support application in northern Nigeria: a pre/post-intervention study. PLOS one, 10(5), 10.1371/journal.pone.0123940 https://doi.org/10.1371/journal. pone. 0123940

[16] Jalloh-Vos, H., Ormel, H., de Koning, K., Jalloh, A. M., Herschderfer, K., Khadduri, R., Maldonado, F., Kamara, S. A. Y., Jalloh, A. K., Wolmarans, L., Leigh, B., Magbity, E., Daniels, D., van Beijma, H., Kargbo, S., Palmar, I., Foray-Rahall, L., \& Hessels, P. (2014). Mobile health: Connecting managers, service providers and clients in Bom-bali district, Sierra Leone. Final report. Amsterdam: DFID New and Emerging Tech-nologies Research Competition, Phase 2.

[17] Higgs, E. S., Goldberg, A. B., Labrique, A. B., Cook, S. H., Schmid, C., Cole, C. F., \& Obregón, R. A. (2014). Understanding the role of mHealth and other media interven-tions for behavior change to enhance child survival and development in low-and middle-income countries: an evidence review. Journal of health communica-tion, 19(sup1), 164-189.

[18] Hall, C. S., Fottrell, E., Wilkinson, S., \& Byass, P. (2014). Assessing the impact of mHealth interventions in low-and middle-income countries-what has been shown to work?. Global health action, 7(1), 25606. https://doi.org/10.3402/gha.v7.25606

[19] Agus, Y., \& Horiuchi, S. (2012). Factors influencing the use of antenatal care in rural West Sumatra, Indonesia. BMC pregnancy and childbirth, 12(1), 9. https://doi.org/10.1186/ 1471-2393-12-9

[20] Roozbeh, N. (2016). Explaining the preconception care utilization barriers, design, check of psychometric specifications, implementation tools and provide effective strategy. $\mathrm{PhD}$. Thesis School of Nursing and Midwifery Shahid Beheshti University of Medical Sciences, 204-219. 
[21] Jayaseelan, R., Pichandy, C., \& Rushandramani, D. (2015). Usage of Smartphone Apps by Women on Their Maternal Life. Research Journal of Science and Technology, 7(3), 158. https://doi.org/10.5958/2349-2988.2015.00022.4

[22] Berhan, Y., \& Berhan, A. (2014). Antenatal care as a means of increasing birth in the health facility and reducing maternal mortality: a systematic review. Ethiopian jour-nal of health sciences, 24, 93-104. https://doi.org/10.4314/ejhs.v24i0.9S

[23] Kuo, M. C., Lu, Y. C., \& Chang, P. (2012). A newborn baby care support app and sys-tem for mHealth. In NI 2012: Proceedings of the 11th International Congress on Nursing Informatics (Vol. 2012). American Medical Informatics Association.

\section{Authors}

Dr. Chen Kim Lim is a Senior Lecturer in Faculty of Arts, Computing and Creative Industry (FSKIK), Universiti Pendidikan Sultan Idris (UPSI), 35900 Tanjong Malim, Perak, Malaysia.

Dr Kian Lam Tan is a Senior Lecturer in Faculty of Arts, Computing and Creative Industry (FSKIK), Universiti Pendidikan Sultan Idris (UPSI), 35900 Tanjong Malim, Perak, Malaysia.

Martin Shafiihuna Haufiku is master student in Faculty of Arts, Computing and Creative Industry (FSKIK), Universiti Pendidikan Sultan Idris (UPSI), 35900 Tanjong Malim, Perak, Malaysia.

Article submitted 03 September 2018. Resubmitted 06 October 2018. Final acceptance 30 October 2018. Final version published as submitted by the authors. 